\title{
Military Service and Amyotrophic Lateral Sclerosis in a Population-based Cohort
}

\section{Citation}

Weisskopf, Marc G., Merit E. Cudkowicz, and Norman Johnson. 2015. “Military Service and Amyotrophic Lateral Sclerosis in a Population-based Cohort." Epidemiology (Cambridge, Mass.) 26 (6): 831-838. doi:10.1097/EDE.0000000000000376. http://dx.doi.org/10.1097/ EDE.0000000000000376.

\section{Published Version}

doi:10.1097/EDE.0000000000000376

\section{Permanent link}

http://nrs.harvard.edu/urn-3:HUL.InstRepos:25658546

\section{Terms of Use}

This article was downloaded from Harvard University's DASH repository, and is made available under the terms and conditions applicable to Other Posted Material, as set forth at http:// nrs.harvard.edu/urn-3:HUL.InstRepos:dash.current.terms-of-use\#LAA

\section{Share Your Story}

The Harvard community has made this article openly available.

Please share how this access benefits you. Submit a story.

\section{Accessibility}




\title{
Military Service and Amyotrophic Lateral Sclerosis in a Population-based Cohort
}

\author{
Marc G. Weisskopf, ${ }^{\mathrm{a}, \mathrm{b}}$ Merit E. Cudkowicz, ${ }^{\mathrm{c}}$ and Norman Johnson ${ }^{\mathrm{d}}$
}

\begin{abstract}
Background: Military service has been suggested to be associated with an increased risk of amyotrophic lateral sclerosis (ALS), but only one prospective study — of a volunteer cohort — has examined this question. Methods: We prospectively assessed the relation between service in the military and ALS mortality among participants in the National Longitudinal Mortality Study, a population-representative cohort of U.S. men and women surveyed from 1973 through 2002. Participant follow-up was conducted from 1979 through 2002 for ALS mortality. There were 696,743 men and 392,571 women who were 25 years old or more with military service data. In this group, there were 375 male ALS deaths and 96 female ALS deaths. Adjusted hazard ratios (HRs) were calculated using Cox proportional hazards.

Results: Men who served in the military had an increased adjusted ALS death rate [HR: $1.23 ; 95 \%$ confidence interval (CI): 0.98 , 1.53] compared with those who did not serve. An increase in ALS mortality was found among those who served during World War II (HR: 1.47 ; 95\% CI: $1.13,1.91)$ but not during other time periods. This pattern of results was similar for women, but with larger confidence intervals (HR for military service: 1.26 ; 95\% CI: 0.29, 5.59; HR for service during World War II: 2.03 ; 95\% CI: 0.45, 9.05).

Conclusions: Military personnel have an increased risk of ALS, which may be specific to certain service periods although there was no data on actual deployment. Because of the longer follow-up time for World
\end{abstract}

Submitted 10 November 2014; accepted 30 July 2015.

From the aDepartment of Epidemiology, Harvard T.H. Chan School of Public Health, Boston, MA; ${ }^{b}$ Department of Environmental Health, Harvard T.H. Chan School of Public Health, Boston, MA; 'Department of Neurology, Massachusetts General Hospital, Boston, MA; and ${ }^{\mathrm{d} C e n t e r}$ for Administrative Records and Applications, US Bureau of the Census, Washington, DC.

This work was supported by grant \#MDA239243 from the Muscular Dystrophy Association, NIH grant \#NS 082105, and funding from the Agency for Toxic Substances and Disease Registry's National ALS Registry program. The funders had no role in the design and conduct of the study; collection, management, analysis, and interpretation of the data; preparation, review, or approval of the manuscript; nor in the decision to submit the manuscript for publication.

The authors report no conflicts of interest. This paper is released to inform interested parties of research and to encourage discussion. Any views expressed on statistical, methodological, technical, or operational issues are those of the authors and not necessarily those of the U.S. Census Bureau.

Correspondence: Marc G. Weisskopf, Department of Environmental Health, T.H. Chan Harvard School of Public Health, EOME, Landmark Center, 3rd Floor East, P.O. Box 15697, Boston, MA 02215. E-mail: mweissko@ hsph.harvard.edu.

Copyright (C) 2015 Wolters Kluwer Health, Inc. All rights reserved. This is an open-access article distributed under the terms of the Creative Commons Attribution-Non Commercial-No Derivatives License 4.0 (CCBY-NC-ND), where it is permissible to download and share the work provided it is properly cited. The work cannot be changed in any way or used commercially.

ISSN: $1044-3983 / 15 / 2606-0831$

DOI: $10.1097 /$ EDE.0000000000000376
War II veterans, we cannot rule out that increased risk for those who served during other periods would be seen with further follow-up.

(Epidemiology 2015;26: 831-838)

myotrophic lateral sclerosis (ALS) is a rapidly progressAing neurodegenerative disease resulting in paralysis and death within 3 years for more than half of patients. ${ }^{1}$ Although there are familial cases of ALS and both autosomal dominant and autosomal recessive transmission has been documented, $90-95 \%$ of cases are sporadic and of unknown etiology, and some role for environmental factors is suspected. ${ }^{1-3}$ Outside of age and male gender, however, nongenetic risk factors for ALS have been hard to identify, in part because of the lack of large-scale studies with prospectively collected data. ${ }^{2}$ One possible risk factor that has generated much interest, but for which the data are still limited, is military service. Two publications of Gulf War veterans suggested an increased risk among veterans deployed during the first Gulf War., ${ }^{4,5}$ Later, the only prospective cohort study to address this issue found an increased risk for military service in general although Gulf War veterans were not part of the cohort. ${ }^{6}$

The prospective cohort study of the association between military service and ALS among veterans from earlier eras than the Gulf War found veterans to have a $53 \%$ increased rate of ALS that appeared largely independent of when a person had served. ${ }^{6}$ That study was based on the Cancer Prevention Study 2 cohort of volunteers recruited in 1982, and it remains the only general population cohort study of this issue, and the only one to consider service other than during the first Gulf War. To explore this question in a large, United States-representative population, we examined the association between military service and risk of ALS among participants in the National Longitudinal Mortality Study (NLMS). The NLMS comprised a random sample of the noninstitutionalized U.S. population and includes more than 2.4 million men and women recruited between 1973 and 2002.

\section{METHODS}

\section{Study Population}

The NLMS is based on a combined multistage stratified probability sample of the civilian noninstitutionalized population of the United States. ${ }^{7,8}$ It consists of U.S. Census Bureau data 
from Annual Social and Economic Supplements that cover the period from March 1973 to March 2002 and Current Population Surveys (CPS) ${ }^{9}$ for February 1978, April 1980, August 1980, December 1980, and September 1985, and one 1980 Census cohort. ${ }^{7,8,10}$ Each survey is a national stratified cluster sample of households surveyed to obtain demographic, economic, and social information about the U.S. population with particular emphasis on employment, unemployment, and other labor force characteristics. The surveys were conducted by personal and telephone interview and have a response rate of approximately 96\%. A subset of participants in each CPS year are included in NLMS. There are 1,132,094 men and 1,226,171 women in the NLMS through 2002. To better ensure that NLMS participants who served in the military would have done so by the time of their survey, we restricted the population to the 703,142 men and 799,506 women who were 25 years old or more at the time of the survey. This age cutoff also would make it more likely that participants' data on other factors like education or smoking would reflect their status in adulthood. Among these participants, 6,399 (0.9\%) men and 406,935 (50.9\%) women did not respond to the question about military service yielding final analytic sample sizes of 696,743 men and 392,571 women. This work was approved by the Institutional Review Board of the Harvard School of Public Health. The surveys used in the NLMS are undertaken to characterize the U.S. civilian, noninstitutionalized population in terms of demographics and employment. Participation is voluntary, and subjects are informed that their data may be linked with other Census data or external data and are provided with the option to opt-out of any data linkage.

\section{Exposure Assessment}

Surveys are conducted with the head of the contacted household or responsible adult (reference person) who responds for all members of the household. Respondents were asked whether or not each household member had served in the U.S. military and the period of their service: World War I, World War II, Korean War, Vietnam era (if service during more than one of these periods was indicated, then the latter one was recorded), or other period. Additional covariates considered were age, sex, race/ethnicity (non-Hispanic white, non-Hispanic black, Hispanic, non-Hispanic other), education (less than high school, high school, some college, college, postgraduate), percent poverty $(\leq 200 \%, 201-300 \%, 301-500 \%,>500 \%)$, marital status (married or not), and home ownership (own home or rent). Percent poverty is the ratio of actual family income to the poverty threshold income defined by the number of people in the household. Smoking data were considered separately because it was only asked on 6 of the surveys. Because of the smaller data size for smoking and the fact that quantity was not updated after the initial questionnaire, we considered smoking as a dichotomous (ever/never) variable.

\section{Case Ascertainment}

Specific cause of death mortality follow-up information for the NLMS was collected by computer matching its records to the
National Death Index (NDI) for the years 1979 through 2002. ${ }^{11}$ The NDI, a national file containing information collected from death certificates, is maintained by the National Center for Health Statistics, Hyattsville, MD. ${ }^{12}$ Because the NDI began in 1979, deaths for NLMS records occurring between 1973 and 1978 were removed from the NLMS using Social Security Administration (SSA) information, which do not include cause of death and therefore cannot be used to determine ALS mortality. NLMS cause of death information was obtained directly from the NDI and coded using the International Classification of Diseases, 9th Revision (ICD-9; deaths before 1999) or 10th Revision (ICD-10; deaths after 1998). ${ }^{13,14}$ Deaths from ALS were defined as ICD-9 code 335.2 or ICD-10 code G12.2 as either the underlying or a contributing cause of death.

\section{Statistical Analysis}

We used Cox proportional hazards modeling for variable entry and censor times with age as the time metameter to estimate adjusted hazard ratios (HR) and 95\% confidence intervals (CI) for ALS mortality. Age at start and end of follow-up was indicated in years. Additional adjustments were made by including other variables in the model. Participants contributed follow-up time from the time of their survey or, for those surveyed before 1979, 1 January, 1979 (the start of electronic NDI data) until the time of death or the last date of NDI linkage. We created missing data indicators for the small amount of missing data $(<4.5 \%$ for any variable). All models were checked to insure that they met the proportional hazards assumption using the test statement of the SAS PHREG procedure. We used logistic regression to estimate odds ratios for smoking by military service variables to examine the extent to which smoking was likely to confound our results. All analyses were conducted using weighted data. Initially, each CPS survey is weighted for over and under sampling by age, sex, race, Hispanic origin, and state of origin to represent the U.S. noninstitutionalized population in the year of the CPS survey. Because for each CPS year, only a subset of the original CPS is included in the NLMS, the records for each NLMS CPS year are reweighted to reflect that year's U.S. noninstitutional population. Then, because the NLMS CPS sample sizes differ, when various NLMS CPS samples are combined for analysis purposes, the NLMS CPS record weights are readjusted to account for the size of each NLMS CPS file. In this way, the NLMS maintains the representativeness of the U.S. noninstitutionalized population when combining NLMS CPS years of varying sizes. Weights are then scaled to reflect the final sample size of the records involved in an analysis so that the program will be able to generate valid, model-based, variance estimates of parameters.

We performed several sensitivity analyses. To include more NLMS participants, we also included those who were ages 18-24 years at the time of the survey. To minimize prevalent ALS cases, we excluded the first 5 years of follow-up. To maximize correct capture of ALS on the death certificate, we limited follow-up to age 75 . To minimize data reporting 
errors, we restricted to the household reference person. To minimize confounding, we also ran analyses restricted to nonHispanic whites and to those with more than a high school education, and we ran analyses with adjustment for marital status and home ownership to better capture socioeconomic status. We also adjusted for smoking status in analyses among the subset with smoking data. All analyses were conducted with SAS version 9.1 (Cary, NC).

\section{RESULTS}

Among the 696,743 male and 392,571 female NLMS participants at least 25 years of age at their recruitment and who responded to the military service question, we identified 375 ALS deaths among men and 96 among women in 9,044,064 person-years of follow-up among men [mean $=13.0$ years per person, standard deviation $(\mathrm{SD})=7.6]$ and $3,204,464$ years of follow-up among women (mean $=8.2$ years per person, $\mathrm{sd}=5.1)$. The mean age of the full population of men at recruitment was 47 years $(s d=16)$, and the mean age of women was 49 years $(\mathrm{sd}=17)$. The ALS mortality rates among men and women in this population peaked in the 75-84 years of age range (Figure). Compared with men and women who did not serve in the military, slightly more of those who served were non-Hispanic white, had higher income, and were more likely to have never been married (Table 1). Men who served tended more often to own their home, and women who served tended to be more educated than those who did not. Among men who served in the military most served during World War II, whereas

TABLE 1. National Longitudinal Mortality Study Participant Characteristics by Gender and Military Service

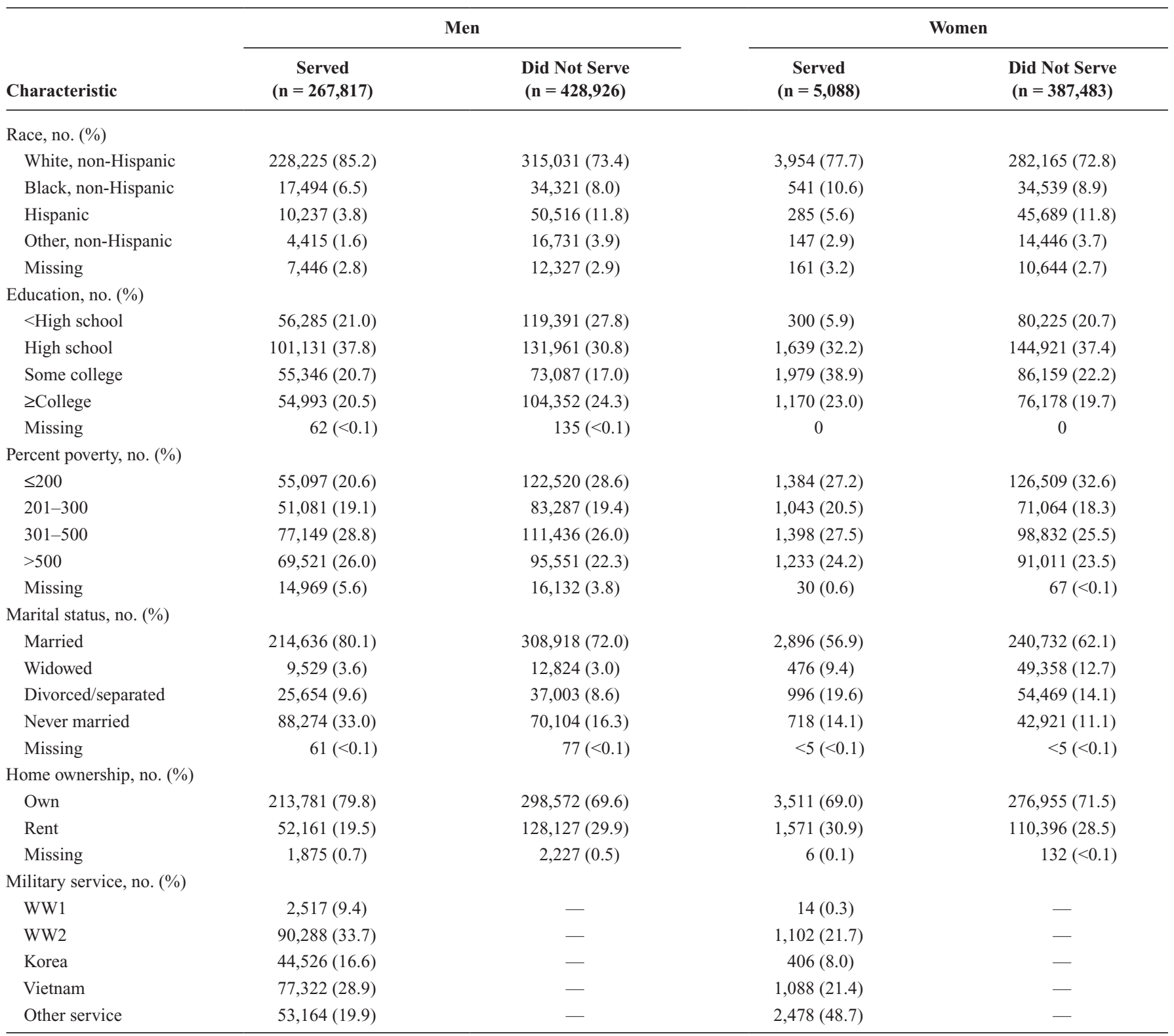


most women who served did so outside of the periods of the World War I, World War II, Korea, or Vietnam eras. Among NLMS participants with military data, there were 150,579 deaths from any cause among men and 35,317 among women. After adjusting for race, education, and poverty the overall (not ALS only) mortality rate of veterans compared with nonveterans was slightly elevated among men (HR: 1.06; 95\% CI: 1.05, 1.07 ) and women (HR: $1.08 ; 95 \%$ CI: 0.99, 1.19).

Among the 375 men who died from ALS, 221 were among men who served in the military and 154 among those who did not. The age-adjusted HR for ALS among men who served in the military compared with those who did not was 1.33 (95\% CI: 1.07, 1.65; Table 2). Additional adjustment for race, education, and percent poverty reduced the HR somewhat $(1.23 ; 95 \%$ CI: $0.98,1.53)$. When considering service during specific periods, the increased rate of ALS was largely restricted to those who served during World War II among whom the HR was 1.47 (95\% CI: 1.13, 1.91) although the rate among Korean War era veterans was slightly elevated, and there were too few who served during World War I to estimate an HR for this group (Table 2). This general pattern held for women as well although there were fewer women and so much wider CI. The adjusted HR for ALS among women who served in the military $(\mathrm{n}=2$ ALS deaths, both among World War II veterans) compared with those who did not $(\mathrm{n}=94$ ALS deaths) was 1.26 (95\% CI: 0.29, 5.59). The estimates for specific periods were inestimable for all periods except World War II, for which the HR was 2.03 (95\% CI: 0.45, 9.05). In analyses that combined men and women, the age, sex, race, education, and percent-poverty adjusted HR for military service was 1.20 (95\% CI: 0.97, 1.50), and only service during World War II was elevated without the $95 \%$ confidence interval (95\% CI) including 1 (HR: 1.39; 95\% CI: 1.08, 1.79).

We performed several additional sensitivity analyses. In analyses that assumed women who did not respond to the military service question had in fact not served, the results were essentially the same (HR: 1.26 ; $95 \%$ CI: $0.29,5.42$ ). Sensitivity analyses among men are shown in Table 3. Results were largely unchanged in analyses that included those ages 18-24 at the time of survey or excluded the first 5 years of follow-up for all participants to exclude those who may have had ALS at the time of the baseline survey. Results were also similar when limiting followup to age 75 or the period of ICD-9 use (through 1998); restricting to non-Hispanic whites, to the household reference person, or to those with more than a high school education; or when additionally adjusting for marital status and home ownership.

Tobacco use questions were asked of only a subset of NLMS participants. Among this subset $(n=159,789)$, those who served in the military were just more than 2 times as likely to smoke cigarettes as those who did not serve in the military, and this was largely independent of which period they served, with World War II veterans smoking somewhat less than Korean or Vietnam era veterans (Table 4). Although the number of ALS deaths $(n=53)$ was small among the subset with smoking data, the military-ALS association results were similar but with larger confidence intervals. When adjusting for smoking as well as race, education, and percent poverty the HR for ALS among those who served in the military was 1.06 (95\% CI: 0.59, 1.90) and for service during World War II was 1.57 (95\% CI: $0.73,3.39)$. Without adjusting for smoking among this same subset of NLMS participants, the HRs were $1.09(0.61,1.95)$ and $1.61(0.75,3.48)$, respectively.

\section{DISCUSSION}

In this prospective study of a U.S. representative population, we found an increased rate of ALS mortality among those who served in the military that was robust to several sensitivity analyses. The age- and sex-specific rates of ALS mortality in this population are comparable with U.S. national mortality statistics, ${ }^{15,16}$ as expected, and are slightly shifted to older ages compared with typical incidence rates ${ }^{3}$ as expected given the time interval between incidence and death. The period of service among the men in our study was weighted toward the World War II era although the NLMS includes veterans of the Korean and Vietnam eras as well, and World War I, although the number with service during World War

TABLE 2. Hazard Ratios and $95 \% \mathrm{CI}$ for ALS by Military Service Among Men

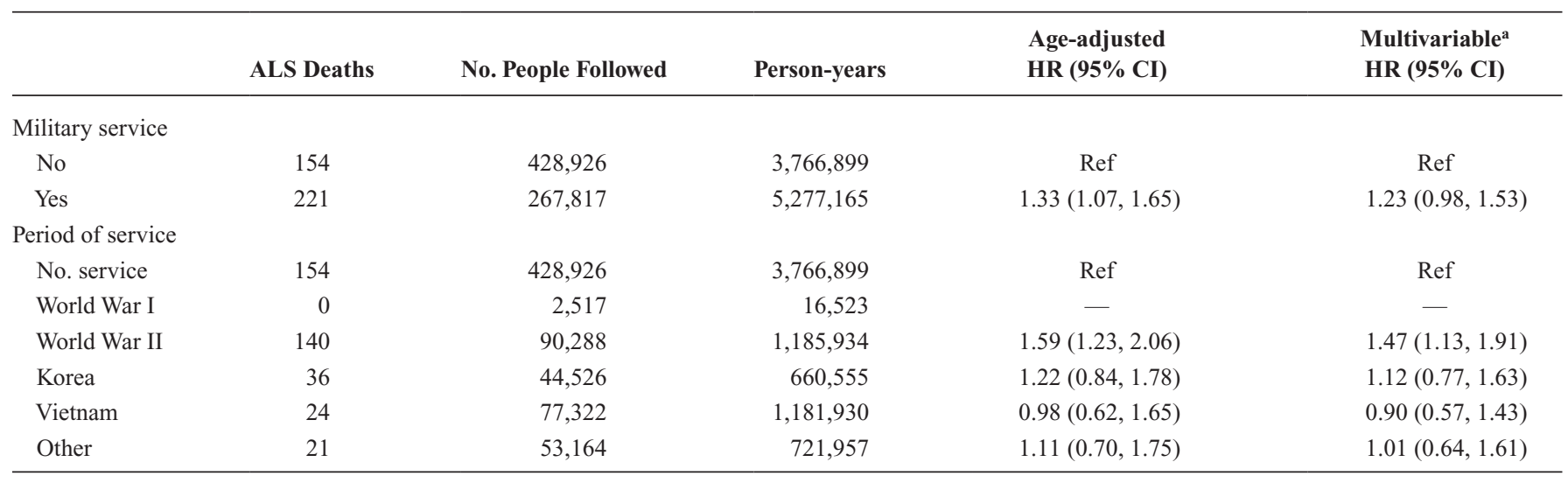

${ }^{\text {a} A d d i t i o n a l l y ~ a d j u s t e d ~ f o r ~ r a c e, ~ e d u c a t i o n, ~ a n d ~ p e r c e n t ~ p o v e r t y . ~}$ 
TABLE 3. Adjusted ${ }^{\mathrm{a}} \mathrm{HR}$ and $95 \% \mathrm{Cl}$ for ALS by Military Service, for Different Models

\begin{tabular}{|c|c|c|c|c|c|}
\hline & ALS Deaths & No. People Followed & Person-years & $\begin{array}{c}\text { Military Service HR } \\
(95 \% \text { CI) }\end{array}$ & $\begin{array}{c}\text { World War II Service } \\
\text { HR }(95 \% \text { CI })\end{array}$ \\
\hline $\begin{array}{l}\text { Including those ages } \\
18-24 \text { at survey }\end{array}$ & 380 & 829,801 & $11,233,211$ & $1.27(1.01,1.58)$ & $1.50(1.15,1.95)$ \\
\hline $\begin{array}{l}\text { Excluding first } 5 \text { years of } \\
\text { follow-up }\end{array}$ & 271 & 548,978 & $8,659,994$ & $1.16(0.89,1.51)$ & $1.42(1.03,1.97)$ \\
\hline Follow-up to age 75 only & 269 & 654,413 & $8,811,630$ & $1.20(0.92,1.56)$ & $1.55(1.12,2.14)$ \\
\hline $\begin{array}{l}\text { Follow-up through } 1998 \\
\text { (ICD-9 only) }\end{array}$ & 268 & 608,786 & $6,957,619$ & $1.26(0.96,1.64)$ & $1.47(1.08,1.99)$ \\
\hline Non-Hispanic white only & 329 & 543,235 & $7,235,789$ & $1.15(0.90,1.45)$ & $1.34(1.02,1.76)$ \\
\hline Reference person only & 347 & 581,367 & $7,839,602$ & $1.25(0.99,1.58)$ & $1.45(1.10,1.90)$ \\
\hline$>$ High school education & 130 & 287,765 & $3,728,623$ & $1.28(0.87,1.89)$ & $1.72(1.05,2.82)$ \\
\hline Additional adjustments ${ }^{\mathrm{b}}$ & 375 & 696,714 & $9,044,064$ & $1.22(0.98,1.53)$ & $1.47(1.13,1.91)$ \\
\hline
\end{tabular}

I was too small to draw inferences. Because NLMS recruitment continued through 2002, some of our population may have served in the first Gulf War, although this would be a much smaller percentage and participants were not specifically asked about service during that period. The excess risk of ALS that we found seemed specific to those who had served in World War II, although the risk among Korean War era veterans was slightly, but not statistically, elevated. The World War II era veterans by definition had the longest follow-up and the Korean War era veterans the next longest, so it remains possible that with further follow-up, increased rates could be seen among veterans of periods other than World War II. The pattern of results appeared similar for men and women, although there were very few women in the NLMS who served in the military, so the results among women must be viewed with caution.

Initial reports suggested that veterans who had been deployed to the Gulf were about twice as likely to develop ALS as either nondeployed veterans of the Gulf ${ }^{4}$ or the general U.S. population. ${ }^{5}$ Critiques of these studies were raised, particularly related to possible underascertainment of ALS, ${ }^{17,18}$ although a subsequent paper explored this issue and concluded that the underascertainment would have had to be rather large to have accounted for the original findings. ${ }^{19}$ However, one subsequent report suggested that the increased risk of ALS among the veterans was limited to about a decade after deployment, ${ }^{20}$ and another found no increase in ALS mortality among veterans of the first Gulf War in analyses that looked at 13 years of follow-up. ${ }^{21}$

The association with military service in general was addressed in the Cancer Prevention Study 2, a volunteer cohort that included more than 500,000 men recruited in 1982 among whom essentially all military service was before the Gulf War. ${ }^{6}$ Those who served were found to be at $53 \%$ increased risk of ALS. The increased risk appeared largely independent of the war period of service, although the elevated risk for service during World War II (1.60; 95\% CI: $1.12,2.30$ ) was slightly larger and had a narrower CI than for those who served during the Korean War $(1.54 ; 95 \%$ CI: 0.92 , $2.60)$ or the Vietnam War $(1.44 ; 95 \%$ CI: $0.47,4.47)$. The volunteer nature of the Cancer Prevention Study 2 study has been raised as a concern, ${ }^{22}$ although as the recruitment was before ALS, it is not straightforward to see how an association would be created where one did not exist. ${ }^{23}$ One other study found no increased risk of ALS among French military personnel. ${ }^{24}$ However, case ascertainment was limited to those still active and receiving military healthcare, and thus, many cases may have been missed thus biasing rates downward.

Our current findings are generally consistent with those of the Cancer Prevention Study 2 except that we found a weaker association among Korean War veterans and no association among Vietnam veterans despite more ALS deaths in that group in the NLMS than in the Cancer Prevention Study 2 cohort. Characteristics of the 2 populations differed somewhat, with the Cancer Prevention Study 2 population being about 10 years older at baseline, more predominantly white, and with more education than the NLMS population. However, our results did not indicate much difference in rate of ALS when stratified on these factors in the NLMS. so it would seem unlikely that these differences would explain the differences by service period. The Cancer Prevention Study 2 analysis also only included deaths through 1998 and thus coded with ICD-9. Although differences in case identification with ICD-10 are possible, this did not seem to account for our findings because results were similar when restricted to deaths coded with ICD-9.

In contrast to the studies that focused on veterans of the Gulf War, but similar to the Cancer Prevention Study 2 study, in the NLMS, service during different war periods was inferred from dates of service, and we did not have data on actual deployment during military service. Thus, if some aspect of deployment is related to increased risk of ALS, results in our study would have been attenuated because nondeployed veterans 
TABLE 4. $\quad$ Adjusted ${ }^{\mathrm{a}}$ Odds Ratio (OR) and 95\% Cl for Smoking by Military Service Among Men

\begin{tabular}{lccc}
\hline & Smokers & Nonsmokers & OR (95\% CI) \\
\hline $\begin{array}{l}\text { Military service } \\
\text { No }\end{array}$ & 53,000 & & Ref \\
Yes & 36,631 & 53,460 & $2.10(2.05,2.15)$ \\
Period of service ${ }^{b}$ & & 16,698 & \\
No service & 53,000 & 53,460 & $2.01(1.93,2.09)$ \\
World War II & 10,515 & 4,342 & $2.54(2.42,2.67)$ \\
Korea & 6,279 & 2,351 & $2.39(2.31,2.48)$ \\
Vietnam & 11,505 & 5,147 & $1.71(1.64,1.77)$ \\
Other & 8,287 & 4,799 & \\
\hline aAdjusted for race, education, and percent poverty. & & & \\
bThose serving during World War I are not shown. & & & \\
\hline
\end{tabular}

were combined with those who were deployed. An additional limitation of our study - similar to that of the Cancer Prevention Study 2 - was that follow-up was limited to mortality data. However, because survival with ALS is very short, ${ }^{3}$ mortality is thought to be a reasonable surrogate for incidence. ${ }^{25}$ Death certificate data have been estimated to accurately identify roughly $70-90 \%$ of ALS or motor neuron disease cases. ${ }^{26,27}$ Although a small number of ALS cases in the NLMS may have been missed, this would be unlikely to bias the risk estimates unless the misclassification was strongly related to military service (or a given subgroup of interest). These are unlikely scenarios given the dramatic nature and time course of ALS. Furthermore, in analyses restricting follow-up to age 75 , the results were similar. At these younger ages, the diagnosis of ALS is much more certain and thus even more likely to be equal across exposure variable groups. ${ }^{28,29}$ Relying on mortality, however, does mean we cannot distinguish associations with incidence and those with survival. Our findings could also be explained by decreased survival with ALS among those who served in the military, particularly during World War II. We also cannot completely exclude the possibility that the higher rate among the earlier veterans relates to better health care and thus better ALS identification, among veterans of earlier eras compared with the general population. However, such a difference might be expected to be minimized among the more highly educated, yet our results were slightly stronger when restricted to NLMS participants with higher education levels. Lastly, NLMS data are limited to that obtained from the reference person for others in the household. In general for occupational and demographic data, studies have found surrogate responses to be very reliable with little systemic bias, ${ }^{30-32}$ but some error still could occur. This would likely be nondifferential and so bias results toward the null. Furthermore, results of our sensitivity analysis just among the reference people were virtually unchanged from the main analysis.

An additional limitation is the very limited data on cigarette smoking. There is some evidence that cigarette smoking is associated with an increased risk of ALS, although

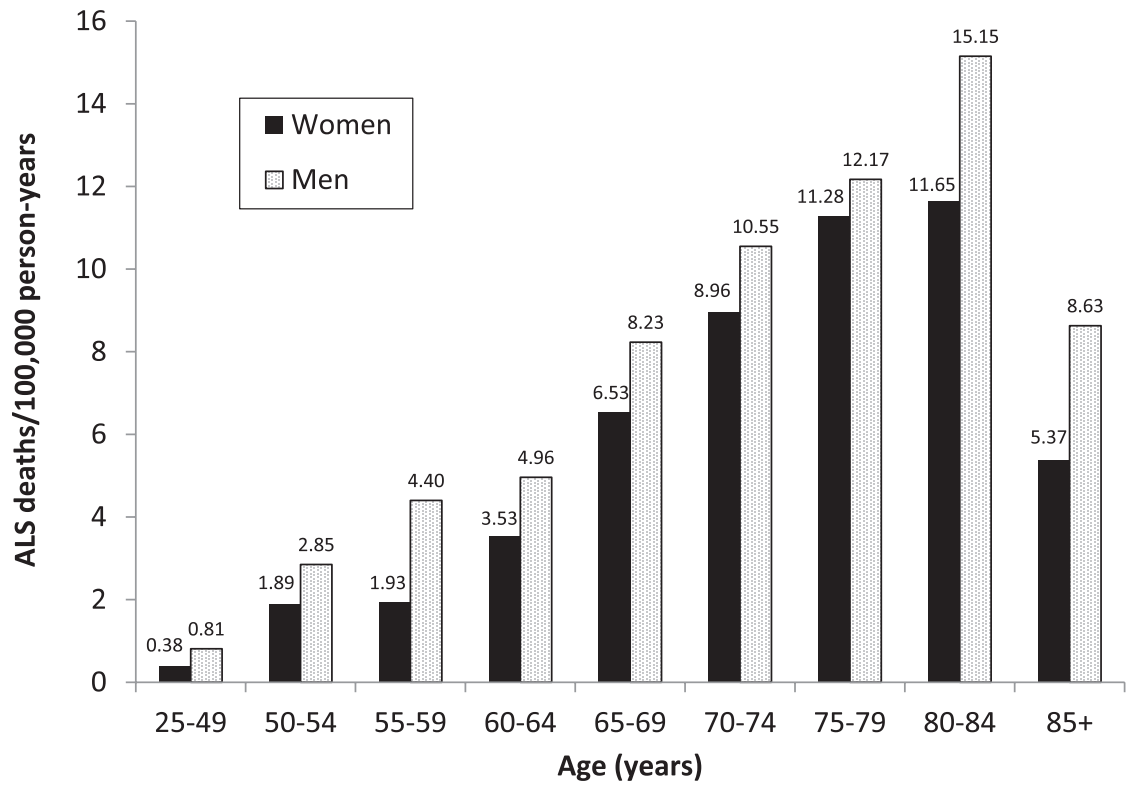

FIGURE. Amyotrophic lateral sclerosis death rates by age group among U.S. men and women from the National Longitudinal Mortality Study cohort at least 25 years of age and with data on military service, 1979-2002. 
inconsistencies in the literature still exist including several studies that show no association among men. ${ }^{33-38}$ There is a strong association between military service and cigarette smoking that is seen in our data, which leaves open the possibility of some uncontrolled confounding by smoking. In the smoking-adjusted analyses, the results for any military service are reduced from the main analyses, whereas the results for World War II are not much different. However, neither result is much different from results among the same NLMS subset, but not adjusted for smoking. Thus, the lower effect estimate for any military service is likely more the result of fluctuation as a result of a much smaller sample size. Also arguing against confounding by smoking is that the greater smoking among military personnel was virtually the same across periods of service and if anything slightly less among those who served during World War II than those who served during the Korean and Vietnam Wars. Thus, if smoking were confounding our findings, it would be expected to create an association with service during the Korean and Vietnam Wars as well as World War II, which we did not see. Thus, confounding of our results by cigarette smoking seems unlikely.

Major strengths of our study include the very large size, and that it is a U.S. representative population. As such, our findings add strong weight to the association between some aspect of military service and the risk of ALS, although it cannot determine what the causative factor or factors are. Possibilities raised for etiologic factors in the prior studies of veterans have included neurotoxic agents during the Gulf War, ${ }^{4,5}$ including possibly cyanobacterial toxins such as beta- $N$-methylaminoL-alanine (BMAA) ${ }^{39}$ or exposures more common to many military eras such as the insect repellant $N, N$-diethyl- $m$-toluamide (DEET), exposures to lead, other chemicals, traumatic brain injury, viral infections, or strenuous activity. ${ }^{40-42}$ If the results of our study are to be taken at face value, identification of exposures specific to the World War II era should be a priority.

\section{REFERENCES}

1. Al-Chalabi A, Hardiman O. The epidemiology of ALS: a conspiracy of genes, environment and time. Nat Rev Neurol. 2013;9:617-628.

2. Factor-Litvak P, Al-Chalabi A, Ascherio A, et al. Current pathways for epidemiological research in amyotrophic lateral sclerosis. Amyotroph Lateral Scler Frontotemporal Degener 2013;14(Suppl 1):33-43.

3. Logroscino G, Traynor BJ, Hardiman O, et al. Descriptive epidemiology of amyotrophic lateral sclerosis: new evidence and unsolved issues. J Neurol Neurosurg Psychiatry 2008;79:6-11.

4. Horner RD, Kamins KG, Feussner JR, et al. Occurrence of amyotrophic lateral sclerosis among Gulf War veterans. Neurology 2003;61:742-749.

5. Haley RW. Excess incidence of ALS in young Gulf War veterans. Neurology. 2003;61:750-756.

6. Weisskopf MG, O'Reilly EJ, McCullough ML, et al. Prospective study of military service and mortality from ALS. Neurology 2005;64:32-37.

7. Rogot E, Sorlie PD, Johnson NJ, Schmidt C. A Mortality Study of 1.3 Million Persons by Demographic, Social and Economic Factors: 1979-1985 Follow-up. 2nd Data Book. Bethesda, MD: National Institutes of Health; 1992.

8. Sorlie PD, Backlund E, Keller JB. US mortality by economic, demographic, and social characteristics: the National Longitudinal Mortality Study. Am J Public Health. 1995;85:949-956.
9. US Bureau of the Census. Current Population Survey: Design and Methodology. Washington, DC: US Department of Commerce; 2000.

10. US Bureau of the Census. The Current Population Survey: Design and Methodology. Washington, DC: US Department of Commerce; 1978.

11. Rogot E, Sorlie P, Johnson NJ. Probabilistic methods in matching census samples to the National Death Index. J Chronic Dis. 1986;39: 719-734.

12. National Center for Health Statistics. User's Manual: The National Death Index. Washington, DC: USGPO; 1990.

13. World Health Organization. International Classification of Diseases Ninth Revision. Manual of the International Statistical Classification of Disease, Injuries, and Causes of Death, 9th Revision. 2nd ed. Vol. 1. Geneva: World Health Organization; 1977.

14. World Health Organization. International Statistical Classification of Diseases and Related Health Problems, Tenth Revision. 2nd ed. Vol. 1. Geneva: World Health Organization; 1992.

15. Sejvar JJ, Holman RC, Bresee JS, Kochanek KD, Schonberger LB. Amyotrophic lateral sclerosis mortality in the United States, 1979-2001. Neuroepidemiology. 2005;25:144-152.

16. Mehal JM, Holman RC, Schonberger LB, Sejvar JJ. Amyotrophic lateral sclerosis/motor neuron disease deaths in the United States, 1999-2009. Amyotroph Lateral Scler Frontotemporal Degener. 2013;14: 346-352.

17. Armon C. Occurrence of amyotrophic lateral sclerosis among Gulf War veterans. Neurology 2004;62:1027-1029.

18. Rose MR. Gulf War service is an uncertain trigger for ALS. Neurology. 2003;61:730-731.

19. Coffman CJ, Horner RD, Grambow SC, Lindquist J; VA Cooperative Studies Program Project \#500. Estimating the occurrence of amyotrophic lateral sclerosis among Gulf War (1990-1991) veterans using capturerecapture methods. Neuroepidemiology. 2005;24:141-150.

20. Horner RD, Grambow SC, Coffman CJ, et al. Amyotrophic lateral sclerosis among 1991 Gulf War veterans: evidence for a time-limited outbreak. Neuroepidemiology 2008;31:28-32.

21. Barth SK, Kang HK, Bullman TA, Wallin MT. Neurological mortality among U.S. veterans of the Persian Gulf War: 13-year follow-up. Am J Ind Med. 2009;52:663-670.

22. Horner RD, Feussner JR, Kasarskis EJ. Prospective study of military service and mortality from ALS. Neurology. 2005;65:180-181; author reply 180 .

23. Ascherio A, Weisskopf MG, O'Reilly EJ, McCullough ML, Calle EE, Thun MJ. ALS and military service. Neurology. 2005;65:972; author reply 972.

24. Drouet A, Desjeux G, Balaire C, Thevenin-Garron V. [Retrospective study of ALS in French military personnel]. Rev Neurol (Paris). 2010;166: 621-629.

25. Marin B, Couratier P, Preux PM, Logroscino G. Can mortality data be used to estimate amyotrophic lateral sclerosis incidence? Neuroepidemiology. 2011;36:29-38.

26. Chiò A, Magnani C, Oddenino E, Tolardo G, Schiffer D. Accuracy of death certificate diagnosis of amyotrophic lateral sclerosis. $J$ Epidemiol Community Health. 1992;46:517-518.

27. Kioumourtzoglou M-A, Seals RM, Himmerslev L, Gredal O, Hansen J, Weisskopf MG. Comparison of diagnoses of amyotrophic lateral sclerosis by use of death certificates and hospital discharge data in the Danish population. Amyotroph Lateral Scler Frontotemporal Degener. 2015;16: 224-229.

28. Traynor BJ, Codd MB, Corr B, Forde C, Frost E, Hardiman O. Incidence and prevalence of ALS in Ireland, 1995-1997: a population-based study. Neurology. 1999;52:504-509.

29. Piemonte and Valle d'Aosta Register for Amyotrophic Lateral Sclerosis (PARALS). Incidence of ALS in Italy: evidence for a uniform frequency in Western countries. Neurology 2001;56:239-244.

30. Villanueva V, Garcia AM. Validity and reliability of surrogate information for controls in a case-control study on Alzheimer's disease. J Alzheimers Dis. 2006;10:409-416.

31. Debanne SM, Petot GJ, Li J, et al. On the use of surrogate respondents for controls in a case-control study of Alzheimer's disease. J Am Geriatr Soc 2001;49:980-984.

32. Chong JP, Turpie I, Haines T, et al. Concordance of occupational and environmental exposure information elicited from patients with Alzheimer's disease and surrogate respondents. Am J Ind Med 1989;15: 73-89. 
33. Weisskopf MG, McCullough ML, Calle EE, Thun MJ, Cudkowicz M, Ascherio A. Prospective study of cigarette smoking and amyotrophic lateral sclerosis. Am J Epidemiol. 2004;160: 26-33.

34. Fang F, Bellocco R, Hernán MA, Ye W. Smoking, snuff dipping and the risk of amyotrophic lateral sclerosis-a prospective cohort study. Neuroepidemiology. 2006;27:217-221.

35. Gallo V, Bueno-De-Mesquita HB, Vermeulen R, et al Smoking and risk for amyotrophic lateral sclerosis: analysis of the EPIC cohort. Ann Neurol 2009;65:378-385.

36. Alonso A, Logroscino G, Hernán MA. Smoking and the risk of amyotrophic lateral sclerosis: a systematic review and meta-analysis. $J$ Neurol Neurosurg Psychiatry. 2010;81:1249-1252.

37. Alonso A, Logroscino G, Jick SS, Hernán MA. Association of smoking with amyotrophic lateral sclerosis risk and survival in men and women: a prospective study. BMC Neurol. 2010;10:6.
38. Wang H, O'Reilly EJ, Weisskopf MG, et al. Smoking and risk of amyotrophic lateral sclerosis: a pooled analysis of 5 prospective cohorts. Arch Neurol 2011;68:207-213.

39. Cox PA, Richer R, Metcalf JS, Banack SA, Codd GA, Bradley WG. Cyanobacteria and BMAA exposure from desert dust: a possible link to sporadic ALS among Gulf War veterans. Amyotroph Lateral Scler. 2009;10(Suppl 2):109-117.

40. Ravits J. Sporadic amyotrophic lateral sclerosis: a hypothesis of persistent (non-lytic) enteroviral infection. Amyotroph Lateral Scler Other Motor Neuron Disord. 2005;6:77-87.

41. McGuire V, Nelson LM. Epidemiology of ALS. In: Brown RH, M. S, Pasinelli P, eds. Amyotrophic Lateral Sclerosis. Boca Raton, FL: Informa Healthcare, 2006;17-41.

42. Johnson FO, Atchison WD. The role of environmental mercury, lead and pesticide exposure in development of amyotrophic lateral sclerosis. Neurotoxicology. 2009;30:761-765. 